\title{
Fluid and Electrolyte Homeostasis in Newborn Baby
}

\author{
Jagadish C Das
}

\begin{abstract}
Summary:
Assessment of fluid and electrolyte properly in neonate is very important but difficult. Fluid and electrolyte homeostasis during this period depends on some factors notably gestational age of baby, its postnatal age, pathological conditions and environmental situation. In fetus, water and electrolytes is constantly supplied from mother, which is cut-off by delivery of the baby. Extracellular fluid volume that is greater than intracellular fluid volume in fetus precipitously decreases after birth. Adaptation of fluid and electrolyte after birth is due to discontinuation of placental exchange, onset of insensible water loss, thermoregulation, autonomic renal regulation and intake of fluid and other nutrients. The adaptation
\end{abstract}

\section{Introduction:}

Fluid and electrolyte assessment during neonatal period is very important and difficult. This is because the transition from fetal to neonatal period is associated with major changes in water and electrolyte homeostatic control. The fetus has a constant water and electrolyte supply from mother across the placenta. After birth, the newborn must acquire responsibility for its own. fluid and electrolyte homeostasis in an environment where fluid and electrolyte availability and losses fluctuate widely. Proportion of various constituents of such environment varies normally depending on gestational age of neonate and even on postnatal age of baby. It also varies during pathological situations and environmental conditions. Again, relative small absolute changes in body water and electrolyte represent as large proportionate change in a neonate due to its small body size ${ }^{1}$. So careful fluid and electrolyte management is essential for the well being of sick neonate. Inadequate administration of fluids can result in hypovolemia, hypersomolarity, metabolic abnol-111alities and renal failure in neonate whereas excess fluid administration may results generalized edema and abnormalities of

Address for correspondence: Dr. Jagadish C Das, Sattar Manson (3rd floor), Nabab Sirajdullah Road, Chakbazar, Chittagong, Bangladesh. Phone: 0088- 01711 077900, E-mail: jagadishcdas@yahoo.com

Received: 08 July, 2007

Accepted: 01 October, 2007 course is divided into transition phase, intermediate phase and stable growth phase. Fluid and electrolyte therapy in neonate should be very judicious, because administration of minimum fluid and electrolyte may bring a maximum proportionate change of such environment. Fluid requirement in neonate after birth increases gradually by first few days. Preterm baby require more fluid than term baby during the first week of life due to high insensible water loss in the former. Electrolytes with intravenous fluid should be offered after ensuring initial diuresis, a decrease in sodium or at least 5-6\% weight loss in neonates.

Key word: Fluid, electrolyte, homeostasis, newborn baby.

(J Bangladesh Coll Phys Surg 2008; 26: 39-45)

pulmonary function. Excess fluid in newborn infant is also associated with patent ductus arteriosis, congestive heart failure, intraventricular hemorrhage, necrotizing enterocolitis and bronchopulmonary dysplasia $(\mathrm{BPD})^{2}$. Electrolyte abnormality in neonatal period is quite undesirable. Sodium is a permissive factor for growth and depletion of sodium in this period is associated with poor weight gain along with other abnormalities ${ }^{2}$. Though both Hyponatranlia and hypernatramia contribute to neurological morbidity in sick neonate ${ }^{2}$, prevalence of hypematramia $\left(7.1 / 100000\right.$ term baby $^{3}$ or $274 / 100$ 000 term baby $^{4}$ ), fluid and other electrolyte abnormality is not less even in developed nations ${ }^{2}$. Minerals are essential for healthy life, but its administration within few hours of life is associated with adverse effect on neonatal health ${ }^{2}$. So, fluid and electrolyte management in neonatal period should be very judicious and thus is ever encountered in medicine. The goal is not to maintain fluid and electrolyte status after birth, rather to allow the changes to occur appropriately. Shortage of understanding of health clinicians regarding fluid and electrolyte homeostasis of newborn baby will make an adverse effect on newborn health. Unfortunately, understanding of many physicians remained incomplete regarding such vital pediatric issue. The review is written to orient and update health personals particularly the clinicians regarding some fundamental aspect of such important topic to help 
neonate through allowing such vital changes to occur appropriately.

\section{Background:}

Total body water (TBW) decreases markedly from intrauterine life to adulthood. Water contributes to $90 \%$ of body weight in the 24 weeks old fetus, $75 \%$ in term neonates, and $50 \%$ in adults'. During intrauterine life water content decreases along with relative increase of fat mass particularly during third trimester of gestation ${ }^{6}$. Water turnover is high in neonates and decreases with increasing age ${ }^{7,8}$. Body water is divided into two compartments: intracellular fluid $(\mathrm{ICF})$ and extracellular fluid $(\mathrm{ECF})^{9}$. In the fetus, the ECF volume is larger than ICF volume, and ECF decreases with age. The ECF volume drops precipitously after birth in large part because of postnatal dieresis. By 1 year of age both fluid compartments come close to adult levels (Fig-1) ${ }^{10}$. The major ion of ECF is sodium $(\mathrm{Na}+)$. Blood volume in neonates is $85-100 \mathrm{ml} / \mathrm{kg}$ body weigh compared to $60-70 \mathrm{ml} / \mathrm{kg}$ body weights in adolescents and adults ${ }^{11}$.

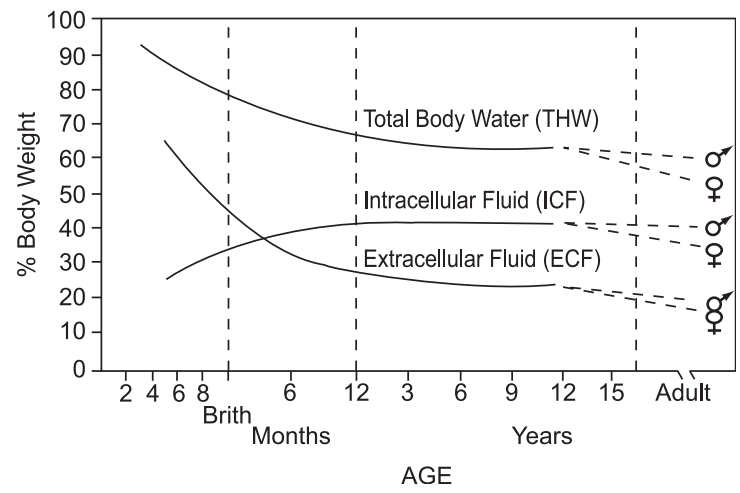

Fig-1: Rearrangement of body fluid from intrauterine to extrauterine life.

Immediate adaptation process after birth affects the metabolism of water and electrolytes as a result of discontinuation of placental exchange and the onset of considerable insensible water loss and thermoregulation. Subsequent adaptation includes the onset of autonomic renal regulation of fluids and electrolytes, and intake of fluids and other nutrients ${ }^{12}$. The time course of adaptation may be divided into three major phases ${ }^{12}$.

*Phase-1 (Transition phase): The immediate postnatal phase is characterized by a relative oliguria ${ }^{13}$ followed by a diuretic phase, during which body fluid compartments are rearranged by isotonic or hypertonic (i.e.hypernatraemic and hyperchloremic) contraction. Duration of this phase varies from hours to days. These changes are caused by considerable evaporative water loss via immature skin and by continuing natriuresis ${ }^{14}$. Phase 1 usually ends when maximum weight loss has occurred ${ }^{12}$. *Phase-II (Intermediate phase): This phase is characterized by diminished insensible water loss along with increasing cornification of epidermis, a fall in urine volume to less than $1-2 \mathrm{ml} / \mathrm{kg}$ per hour, and a low sodium excretion. Duration of this phase varies from 5 to 15 days $^{12}$. *Phase-III (Stable growth phase): This is characterized by continuous weight gain with a positive net balance for water and sodium. Expected weight gain is $10-20 \mathrm{gm} / \mathrm{kg}$ body weights per day ${ }^{12}$.

The renal glomerular surface area available for filtration is small in neonates than that of in older infants and adults. In term neonate, glomerular filtration rate (GFR) increases significantly during the first week of life and continues to rise over the first two years of life ${ }^{12}$. Immaturity to the distal nephron with an anatomically shortened loop of Henle leads to reduced ability to concentrate urine ${ }^{12}$. Maximum urinary concentrations are up to $550 \mathrm{mosm} / 1$ in preterm infants, and $700 \mathrm{mosm} / 1$ in term infants, compared to $1200 \mathrm{mosm} / 1$ in adults ${ }^{15}$. Neonates may be placed at risk for volume depletion when a high renal solute load cannot be compensated for by the ability to produce concentrated urine. Although hormonal factors i.e. renin-angiotensin-aldosterone system (RAAS), and arginin-vasopressin (AVP) is mature early in gestation, the effects are limited by renal immaturity ${ }^{16}$. A lower plasma oncotic pressure and higher permeability of the capillary wall in preterm infants compared to term infants and adults ${ }^{12}$ enhances the shift of water from, intravascular to interstitial compartment, with an increased risk of edema especially under pathologic conditions ${ }^{17}$.

Fluid and electrolyte assessment generally focuses on body water, serum sodium, potassium and calcium concentrations.

Body water and sodium: A weight loss of $5-10 \%$ in term $^{18}$ infants and $10-20 \%$ in preterm ${ }^{19}$ infants is common during the first week of life. The net water and sodium loss is accepted as appropriate after 
birth $^{20}$. Assessment of degree of this water loss is complicated by a relatively large and highly variable insensible water loss ${ }^{1}$. The more immature the infant, the more pronounced the contraction of the extra cellular space and higher the insensible water loss. Both of these factors predispose to hypernatremia in the first few days of life.

Potassium. Serum potassium concentration rise in the first 24 to 72 hours after birth in moderately to markedly premature infants, even in the absence of exogenous potassium intake and in the absence of renal dysfunction ${ }^{21}$. This increase seems to be the result of a shift of potassium from the intracellular to extracellular space. The magnitude of this shift roughly correlates with the degree of immaturity ${ }^{21}$. Potassium load is excreted by the kidneys ${ }^{1}$.

Calcium. Total calcium concentration in cord plasma increases with increasing gestational age and is significantly higher than maternal values ${ }^{1}$. With delivery of baby, plasma calcium falls, reaching a nadir at age 24-48 hour ${ }^{22}$. Serum parathyroid hormones (PTH) increase postnatally in response to this fall in plasma calcium concentration. This increase in PTH mobilizes calcium from bone, and plasma calcium concentration rises and subsequently stabilizes even in the absence of exogenous calcium intake. Clinically significant hypocalcemia occurs in premature infants, asphyxiated newborns, and infants of diabetic mothers. The etiology in all these circumstances is a sluggish response in PTH secretion to the postnatal fall in plasma calcium concentration.

Approximately $50 \%$ of total plasma calcium is bound (predominantly to albumin) and $50 \%$ is ionized. Ionized calcium is the best indicator of physiologic blood calcium activity. Changes in plasma ionized calcium concentration parallel those described above for total plasma calcium concentration ${ }^{23}$. Lower serum albumin concentration and acidosis, not uncommonly found in premature infants, result in a lower total plasma calcium concentration for a given plasma ionized calcium concentration. Changes in ionized plasma calcium mirror to total plasma calcium concentration. Again, larger sample volume is required in many laboratories to determine ionized calcium. Hence, calcium status is routinely monitored with total plasma calcium concentration ${ }^{23}$. In neonates, faecal sodium loss depends on gestational age. The loss is $0.1 \mathrm{mmol} / \mathrm{kg} /$ day in preterm and 0.02 $\mathrm{mmol} / \mathrm{kg} /$ day in term babies $^{12}$. Faecal potassium losses are about twice as high as sodium loss, but show no relation with gestational age ${ }^{12}$. Under pathological conditions (e.g. bowel obstruction, ileostomy, pleural fluid aspiration etc.) electrolyte contents of lost fluids cannot be predicted precisely. Here, it is wise to measure at least once the sodium concentration of such lost fluid in order to replace them. Chloride loss usually correlates with sodium loss and potassium loss is usually much smaller ${ }^{12}$.

\section{Fluid and electrolyte management:}

Management of fluid and electrolyte in neonate should be based on background of such issue. It depends on baby's age, weight, associated pathological situation, environmental conditions and on phase that the baby is passing.

\section{Phase 1: Transition phase}

The objectives for fluid and electrolyte administration during this period are:

- To allow contraction of ECF with negative water balance of not more than $10 \%$ without compromising intravascular fluid volume and cardiovascular function.

- To allow a negative net balance for sodium of 2-5 $\mathrm{mmol} / \mathrm{kg}$ per day for the first postnatal days, to maintain normal serum electrolyte concentration.

- To secure a sufficient urinary output and avoid oliguria $(<0.5-1.0 \mathrm{ml} / \mathrm{kg}$ per hour) for longer than twelve hours.

- To ensure regulation of body temperature by providing enough fluid for transepidermal evaporation.

During phase 1, administration of fluid and electrolytes needs very caution. Clinician is to be judicious enough regarding fluid and electrolytes at the onset of diuresis and in polyuric patient specially in ELBW infant ${ }^{12}$. Fluid load during this phase in healthy preterm neonate range from 96 to 200 $\mathrm{ml} / \mathrm{kg}$ /day from the third day of $\operatorname{life}^{24}$, but rarely exceed $130 \mathrm{ml} / \mathrm{kg}$ per day. The fluid intake dependent on birth weight and increases daily (Table-1) Electrolyte administration during the first 3-5 days 
also depends on maturity and birth weight ${ }^{12}$. Generally, sodium $^{25}$ and potassium $^{12}$ supplementation should be started after ensuring initial diuresis, a decrease of serum sodium or at least $5-6 \%$ weight loss in neonates ${ }^{25}$.

Sodium intake should be restricted in very-low-birthweight (VLBW) babies during the period of ECF contraction until a weight loss of approximately $6-10 \%$ has occured ${ }^{26}$. Fluid restriction reduces chance of patent ductus arteriosus, nacrotizing enterocolitis, death and tends to reduce the risk of bronchopulmonary dysplasia but increases risk of dehydration ${ }^{27}$. A restricted sodium intake has positive effects on oxygen requirements and the risk of later bronchopulmonary dysphasia $^{26}$. Sodium restriction also induces higher risk of development hyponatraemia, and is associated with pontine (brain) myelinolyosis ${ }^{12}$.

\section{Phase II: Intermediate phase}

The objectives for fluid and electrolyte administration during phase ii are to:

- Replete the body for electrolyte losses, replaces actual water and electrolytes.

- Augmentation of oral feedings.

Phase 11l: Stable growth phase -

The objectives for fluid and electrolyte administration during phase I I I are:

- To replace losses of water and electrolytes (maintaining water and electrolytes homeostasis).

- To provide extra water and electrolytes to build up new tissue at intrauterine growth rates.

The recommended fluid intakes in phase II (Table-2) are based on studies suggesting that a daily fluid intake equal to or higher than $170 \mathrm{ml} / \mathrm{kg}$ body weight per day is accompanied by high urinary excretion with negative sodium balance, even if $\mathrm{Na}+$ intake is as high as $10 \mathrm{mmol} / \mathrm{kg}$ body weight per day ${ }^{12}$. Fluid therapy in extremely low birth weight (ELBW) in excess of $200 / \mathrm{ml} / \mathrm{kg} /$ day does not maintain $\mathrm{Na}^{+}$ balance, regardless of the amount of $\mathrm{NaCI}$ provided. It is important to note that ELBW infants require more fluids than recommended during the first week of life for term infants, because of high insensible water $\operatorname{loss}^{28}$. Evaporation of water from upper respiratory passages accounts for approximately one third of net insensible water loss and reaches the level of $0.8-0.9 \mathrm{ml} / \mathrm{kg}$-body weight per hour in premature infants and $0.5 \mathrm{ml} / \mathrm{kg}$ body weight per hour in term babies 12 Electrolytes requirements in preterm very low birth weight baby is less than that of preterm low birth-weight baby ${ }^{12}$.

Fluid requirements during the phase III Table-3 re related to the expected weight gain ${ }^{8}$. Daily sodium requirement in term baby in this stage is $-3 \mathrm{mmol} / \mathrm{kg}$ body weight in comparison to $3-5 \mathrm{mmol} / \mathrm{kg}$ body weight in preterm infant ${ }^{12}$.

Urinary output may be as high as $6.0 \mathrm{ml} / \mathrm{kg}$ per hour of free water in the presence of a total urine production of $9.8 \mathrm{ml} / \mathrm{kg}$ per hour in preterm infants with birth weight $2000 \mathrm{gm}^{28}$. Water loss from stool is negligible in early life prior to establishing enteral feeding. When full enteral feeding is achieved, faecal losses of $5-10 \mathrm{ml} / \mathrm{kg}$ per day are usually assumed to balance metabolic water production ${ }^{29}$. Plasma $\mathrm{Na}+$ concentrations are normal in infants with sodium intake of 1.1-3.0 mmol/ $\mathrm{kg}$ body weight per day and

Table-I

Parenteral fluid and electrolyte intake during the first postnatal week.

Recommended fluid intake ( $\mathrm{ml} / \mathrm{kg}$ body weight per day)

\begin{tabular}{lcccccc} 
Days after birth & 1stday & 2ndday & 3rdday & 4thday & 5thday & 6thday \\
\hline Term neonate & $60-120$ & $80-120$ & $100-130$ & $120-150$ & $140-160$ & $140-180$ \\
Preterm neonate $>1500 \mathrm{~g}$ & $60-80$ & $80-100$ & $100-120$ & $120-150$ & $140-160$ & $140-160$ \\
Preterm neonate $<1500 \mathrm{~g}$ & $80-90$ & $100-110$ & $120-130$ & $130-150$ & $140-160$ & $160-180$ \\
\hline
\end{tabular}

Recommended $\mathrm{Na}+, \mathrm{K}+, \mathrm{Cl}$ " supply (mmol/kg body weight per day)

* $\mathrm{Na}+=0-3(5) \quad * * \mathrm{~K}+=0-3 \quad \mathrm{Cl}-=0-5$ 


\section{Table-II}

Parenteral fluid and electrolyte intake for newborn infants during the intermediate phase.

\begin{tabular}{lcccc}
$\begin{array}{l}\text { Gestational age } \\
\text { Birth weight }\end{array}$ & $\begin{array}{c}\text { Fluid intake } \\
\text { (ml/ kg body } \\
\text { weight/day) }\end{array}$ & $\begin{array}{c}\mathrm{Na}+\text { intake } \\
\text { (mmol/kg body } \\
\text { weight/day) }\end{array}$ & $\begin{array}{c}\mathrm{K}+\text { intake } \\
\text { (mmol/kg body } \\
\text { weight/day) }\end{array}$ & $\begin{array}{c}\text { CI- intake } \\
\text { (mmol/kg body } \\
\text { weight/day) }\end{array}$ \\
\hline $\begin{array}{l}\text { Term neonate } \\
\text { Preterm neonate }\end{array}$ & $140-170$ & $2.0-5.0$ & $1.0-3.0$ & $2.0-3.0$ \\
$>1500 \mathrm{~g}$ & $140-160$ & $3.0-5.0$ & $1.0-3.0$ & $3.0-5.0$ \\
$<1500 \mathrm{~g}$ & $140-180$ & $2.0-3.0(5)$ & $1.0-2.0$ & $2.0-3.0$ \\
\hline
\end{tabular}

Table-III

\begin{tabular}{|c|c|c|c|}
\hline \multicolumn{4}{|c|}{ Potential fluid and electrolyte intake during the first month of life with stable growth } \\
\hline Gestational age & $\begin{array}{c}\text { Fluid intake } \\
\text { (ml/ kg body weight/day) }\end{array}$ & $\begin{array}{c}\mathrm{Na}+\text { intake } \\
(\mathrm{mmol} / \mathrm{kg} \text { body weight /day) }\end{array}$ & $\begin{array}{c}\mathrm{K}+\text { intake } \\
(\mathrm{mmol} / \mathrm{kg} \text { body } \mathrm{wt} / \mathrm{day})\end{array}$ \\
\hline Term neonate & $140-160$ & $2.0-3.0$ & $1.5-3.0$ \\
\hline Preterm neonate & $140-160$ & $3.0-5.0(7.0)$ & $2.0-5.0$ \\
\hline
\end{tabular}

fluid intakes of $140-170 \mathrm{ml} / \mathrm{kg}$ body weight per day ${ }^{12,30}$. There is evidence that fluid intake lower than $140 \mathrm{ml} / \mathrm{kg}$ body weight/day, together with Nay intake of about $1 \mathrm{mmol} / \mathrm{kg}$ body weight per day, is adequate to maintain sodium balance in ELBW neonates ${ }^{31,32}$. There is no increase in morbidity among infants given less $\mathrm{Na}+$ and less fluid ${ }^{33}$. A nonsignificant trend to higher incidence of patent ductus arteriosus and bronchopulmonary dysplasia is observed in infants given more $\mathrm{Na}+$ and more fluid intake $^{12}$. Breast-fed term babies need as little as 0.35 to $0.7 \mathrm{mmol} / \mathrm{kg}$ body weight per day of $\mathrm{Na}$ during the first 4 months of life to achieve adequate growth. A recommendation to provide 1.0 to $2.0 \mathrm{mmol} / \mathrm{kg}$ per day of $\mathrm{NaCI}$ should counter-balance incidental losses from skin or gastrointestinal tract. In preterm infants, a higher growth rate explains a higher sodium requirement ${ }^{12}$.

Preterm infants retain about 1.0 to $1.5 \mathrm{mmol} / \mathrm{kg}$ body weights per day $\mathrm{K}+$, which is about the same as foetal accretion. About 2 to $3 \mathrm{mmol} / \mathrm{kg} /$ day of potassium, which is similar to the amount provided in human milk, is usually recommended for young infant ${ }^{12}$.
During fluid and electrolyte management the clinician has to consider about some important environmental factors, which can potentially influence, such vital issues notably insensible water loss.

* A double wall incubator reduce insensible water loss in VLBW neonate by about $30 \%$ when a humidity of $90 \%$ is used at thereto-neutral temperature. With maturation of the epidermal barrier it is possible to reduce ambient humidity step by step commonly after first 5 days of $\operatorname{life}^{12}$ * Use of waterproof coverings (such as plastic films, plastic blankets, bubble blankets) in addition to treatment in a double wall incubator leads to further reduction of insensible water loss by $30-60 \%{ }^{12}$. $*$ Use of radiant warmers or single wall incubators for VLBW care may increase water loss and impair thermoregulation $^{34}$. * Use of emollient ointments decreases insensible water loss of up to $50 \%$ in open care conditions 35,36 . Endotracheal intubations and mechanical ventilation using warmed and humidified air significantly reduces insensible respiratory water loss by $20 \mathrm{~mm} / \mathrm{kg}$ body weights per day ${ }^{12}$. 


\section{Messages:}

- During delivery of baby the extracellular fluid volume is larger than the intracellular volume.

- Extracellular volume drops precipitously after birth mainly due to postnatal diuresis.

- Adaptation of fluid and electrolytes is due to discontinuation of placental exchange, onset of insensible water loss, thermoregulation, renal regulation and intake of fluid and nutrients.

- Adaptation course is divided into three phasesnamely, transition phase, intermediate phase and stable growth phase.

- Electrolytes generally should be supplemented after ensuring initial diuresis.

- Some environmental factors e.g. incubator care, waterproof coverings, radiant warmers, use of emollient etc potentially influences fluid and electrolyte management.

\section{Conclusion:}

Fluid and electrolyte homeostasis in neonatal period is an important issue. Proportion of various constituents of this environment in neonate is very different from older children. Even in same neonate, this environment changes depending on some factors including postnatal age. A relative small absolute pathological change in any of the constituent of this environment may bring a deleterious effect on neonatal health. During delivery extracellular fluid volume is larger than the intracellular volume which drops precipitously thereafter. Adaptation of fluid and electrolytes is divided into three phases and is due to discontinuation of placental exchange, insensible water loss, thermoreguilation, renal regulation and intake of fluid and nutrients by neonate. After birth if needed, fluid without minerals is supplemented and minerals are added when initial diuresis has occurred. The objective of management of this environment is not to maintain the status after birth but to allow the changes to occur appropriately. Clinician is to be updated enough regarding this change. Proper understanding of fluid and electrolyte homeostasis of newborn baby will make problem related to such environment preventable with a favorable change in neonatal health.

\section{References:}

1. Shaffer SG, Meade VM. Sodium balance and extracellular volume regulation in very low birth infants. J Pediatr 1989; 115: $285-290$.

2. Modi N. Fluid and electrolyte balance. In. Rennie JM. Roberton's Textbook of Neonatology 4th ed. Philadelphia. Elsevier Churchill Livingstone 2005; 335-351.

3. Laing IA, Wong CM. Hypernatraemia in the first few days: is the incidence rising? Archives of Disease in Childhood 2002; 87: F158-162.

4. Oddie S, Richmond S, Coulthard H. Hypernatraemic dehydration and breast feeding: a population study. Archives of Disease in Childhood 2001; 85: 318-320.

5. Fomon SJ, Haschke F, Ziegler EE. Body composition of reference children from birth to age 10 years. Am J Clin Nutr 1982; 35: 1169-1175.

6. Fusch C, Slotboom J, Fuehrer U. Neonatal body composition: dual-energy x-ray absorptiometry, magnetic resonance imaging, and three-dimensional chemical shift imaging versus chemical analysis in piglets. Pediatr Res 1999; 46: 465-473

7. Fusch C, Hangerland E, Scharrer B. Water turnover of healthy children measured by deuterated water elimination. Eur J Pediatr 1993; 152: 110-114.

8. Bernardi JL, Goulart AL, Amancio OM. Growth and energy and protein intake of preterm newborns in the first year of gestation-corrected age. Sao Paulo Med J 2003; 121: 5-8.

9. LinshawMA. Selected aspects of cell volume control in renal cortical and medullary tissue. Pediatr Nephrol 1991; 5: 653-665.

10. Greenbaum LA. Pathophysiology of body fluids and fluid therapy. In. Behrman RE, Kliegman RM, Jenson HB editors. Nelson Textbook of Pediatrics 17th ed. Philadelphia. Saunders; 2004: 191.

11. Nicholson JF and Pesce MA. Laboratory testing in infants and children. In. Behnnan RE, Kliegman RM, Tensor HB editors. Nelson Textbook of Pediatrics 17th ed. Philadelphia. Saunders; 2004: 2393-2505.

12. ESPGHAN. Guidelics on pediatric parenteral nutrition. JPediatr Gastroenterol Nutr 2005; 41: S33-S38

13. Modi N. Development of renal function. Br Med Bull 1988; 44: 935-956.

14. Modi N. Hutton TL. The influence of postnatal respiratory adaptation on sodium handling in pretei-n. neonates. Early Hum Dev 1990; 21: 11-20.

15. Chevalier RL. Developmental renal physiology of the low birth weight pre-tern newborn. J Urol 1996; 156: 714-719

16. Haycock GB Aperia A. Salt and the newborn kidney. Pediatr Nephrol 1991; 5: 65-70.

17. Jobe A, Jacobs H, Ikegami M. Lung protein leaks in ventilated lambs: effects of gestational age. J Appl Physiol 1985; 58: 1246-1251 
18. Podratz RO, Broughton DD, Gustafson DH, Bergstralh EJ, Melton J. Weight loss and body temperature changes in breast-feed and bottle-feed neonates. Clin Pediatr 1986; 25:73-77.

19. Shaffer SG, Quimiro CL, Anderson JV, Hall RT. Postnatal weight changes in low birth weight infants. Peclicztries 1987; 79: 702-705.

20. Lorenz JM. Assessing fluid and electrolyte status in newborn. Clinical Chemistry 1997; 43(i). 205-210.

21. Sato $\mathrm{K}$, Kondo $\mathrm{T}$, Iwao $\mathrm{H}$, Honda $\mathrm{S}$, Ueda $\mathrm{K}$. Internal potassium shift in premature infants; cause of non-oliguric hyperkalemia. JPediatr1995; 126: 109-113.

22. Tsang RC, Chen IW, Freidman MA, Chen L Neonatal parathyroid function: role of gestational and postnatal age. J Pediatr 1973; 83:728-730.

23. Wandrup J, Kroner J, Pryds O, Kstrup KW. Age-related reference values for ionized calcium in the first week of life in premature and full-teen neonates. Scand J Clin Lab Invest 1988; 48: 255-260.

24. Coulthard MG and Hey EN. Effect of varying water intake on renal function in healthy pceterm babies. Arch Dis Child 1985; 60: 614-620.

25. Hartnoll G, Betremieux p, Modi N. Randomized controlled trial of postnatal sodium supplementation in infants of 25 30 weeks gestational age; effects on cardiopulmonary adaptation. Arch Dis Child Fetal Neonatal 2001; 85: F2932.

26. Hartnoll G, Betremieux P, Modi N. Randomized controlled trial of postnatal sodium supplementation on body composition in 25 to 30 week gestational age infants. Arch Dis Fetal Neonatal 2000: 82: F24-28.
27. Bell EF, Acarregui MJ. Restricted versus liberal water intake for preventing morbidity and mortality in preterm infants (Cochrane Review). In. The Cochrane Library, Issue I. Chichester, UK: John Wiley \& Sons Ltd.; 2004.

28. Adamkin DH. Issues in the nutritional support of the ventilated baby. Clin Perinatol 1998; 25: 79-9G.

29. Catzeflis C Schutz Y, Micheli JL. Whole body protein synthesis and energy expenditure in very low birth weight infants. Pediatr Res 1985; 19: 679-687.

30. Polberger SK,Axelsson IA,Raitha NC.Growth of very low birth weight infants on verying amounts of human milk protein. Pediatr Res 1989; 25: 414-119.

31. Costarino AT, Gruskay JA, Corcoran L. Sodium restriction versus daily maintenance replacement in very low birth weight premature neonates: a randomized, blind therapeutic trial. JPedurtr 1992; 120: 99-106.

32. Ekblad H, Kero P, Takala J.Water, Sodium and acid-base balance in premature infants :therapeutical aspects. Acta Pediatr Scand 1987; 76: 47-53.

33. Asanto H, Taki M, Igarashi Y. Sodium Homeostasis in premature infants during the early postnatal period: results of relative low volume of fluid and sodium intake. Pediatr Nephrol 1987; 1: C38

34. Meyer MP, Payton MJ, Salmon A. A clinical comparison of radiant warmer and incubator care for preterm infants from birth to 1800 grams. Pediatrics 2001; 108: 395-401.

35. Lane AT, Drost SS. Effects of repeated application of emollient cream to premature neonates' skin. Pediatrics 1993; 92: 415-419.

36. Nopper AJ, Honrri KA, Sookdeo- Drost S. Tropical ointment therapy benefits in premature Infants. JPediatr 1996; 128: 660-669. 